\title{
A Comprehensive Review on the Application of Mesenchymal Stem Cell in the Treatment of ALS Patients
}

\author{
Shahbeigi Saeed ${ }^{1 *}$, Kianpour Rad Soheila ${ }^{2}$, Kianpour Rad Sima ${ }^{3}$, Mohyeddin Bonab Mandana ${ }^{4}$, Pakdaman Hosein ${ }^{1}$ and Altintas Ayse ${ }^{5}$ \\ ${ }^{1}$ Shahid Beheshti Medical University Research Center, Tehran, Iran \\ ${ }^{2}$ Qazvin University of Medical Science, Qazvin, Iran \\ ${ }^{3}$ Molecular Departments, University of Malaya, Kuala Lumpur, Malaysia \\ ${ }^{4}$ Sinacell Research and Product Company, Tehran, Iran \\ ${ }^{5}$ Neurology Department, Koc University, School of Medicine, Istanbul, Turkey
}

\begin{abstract}
Amyotrophic Lateral Sclerosis (ALS) is a malignant disorder in body which impairs motor neuron activity of body and eventually causes death. Although, many researches have been allocated to discover the molecular basis of ALS, but no definite cure of this fatal disease has been found until present time. The scientific revolution of application of stem cells in medicine has encouraged utilization of such technology to exploit the related medical benefits in ALS therapeutics. The purpose of this review is to explore in detail of any available findings of pre-clinical and clinical expeditions of the medical effects of Mesenchymal Stem Cells (MSCs) on ALS. The review encircles in detail the medical research findings on the immune effects of MSCs in ALS treatment and also the related clinical trial. Also the wide range of overall world impact of the disease at present time and in the future is reviewed.
\end{abstract}

Keywords: Amyotrophic lateral sclerosis; Stem cell revolution; Mesenchymal stem cell; Neurodegenerative disease; Sclerosis; Clinical trial

\section{Background}

Amyotrophic Lateral Sclerosis (ALS), also known as Motor Neuron Disease (MND) and Lou Gehrig's, is a particular neurodegenerative disorder which affects Motor Neurons (MNs) in the primary motor cortex, brainstem, and also spinal cord. It is considered as one of the most common neuromuscular diseases in the world with the incidence of two-three cases out of 100000 and the prevalence reported to be four-six out of 100000 worldwide populations [1]. The results of a study conducted in the United States, suggest that ALS could be race dependent and the relative risk of it is significantly lower among blacks and Asians than the white population [2]. Also Arthur et al. [3], showed that the number of ALS cases across the globe will increase from 222801 in 2015 to 376674 in 2040, showing 69\% increase. The projected increase during this 25 years in this study shows that Libya and Iran, both will suffer the most from ALS among the world countries, with an increase of 117 to $112 \%$, respectively, while Serbia gets the benefit of being at the minimum level (-8\%). Currently available drug which has only modest efficacy on ALS is riluzole which only delays the onset of tracheostomy and ventilator-dependence in the selected patients and may promote patient survival by almost two to three mon without improving their life quality [4]. Today, stem cell therapy is found to be a robust therapy for controlling the symptom of the disease and therefore many related studies have exploited such revolutionary therapy in medicine [5].

\section{MSC: General Overview}

MSCs, also considered as stromal multipotent stem cells, which can be derived from umbilical cord bone marrow, adipose tissue and peripheral blood, are found to have profound biological properties [6]. Such cells were first isolated from Bone Marrow (BM) in 1967. Mareschi et al. [7] demonstrated that MSCs collected from amniotic fluid (AF-MSCs) have more advantageous immunophenotypic and functional characteristics compared to the BM-derived MSCs; hence, they could be proposed in clinical applications. The very low density of MSCs in BM requires isolation and expansion steps before their clinical explotations. They can be cultured and maintained in several passages in plastic-adherent tissue culture flasks and display the typical "fibroblastlike" morphology. Interestingly, they cannot differentiate spontaneously and are specified by the expression of the surface markers from the similar cells [8]. The unique properties of MSCs are their strong tendency to replicate in vitro and develop into more advanced cells, such as osteoblasts, chondrocytes, myocytes, adipocytes and supported hematopoietic stroma at the time when a single Colony-Forming UnitFibroblasts (CFU-F) is re-transplanted in vivo [9]. In addition of their easy and safe isolation and simplicity of the cell's expansion in vitro, they could also be differentiated into neural, glial and astrocytic like cells in vitro and in vivo [10]. Due to lack of tumor formation tendency of such cells in clinical applications, no immunosuppressive therapies are needed. Also, the injected MSCs could be channelled to migrate to the damaged areas to trigger for the neurotrophic factors to be increased which contribute to the healing process [11].

\section{MSCs-Specific Cell Surface Markers}

There is no single, specific marker to identify authentic MSCs, however the International Society for Cellular Therapy (ISCT) provides the following minimum criteria to identify MSCs: 1) They must be plastic-adherent, 2) Over 95\% of the population of the cells should express CD105, CD73 and CD90, but not CD45, CD34, CD14 or CD11b, CD79a or CD19 and HLA class II as measured by flow cytometry. Although there are common thoughts regarding that MSCs are CD34, in vitro characterizations predominantly occur after several passages. Sometimes, freshly extracted stromal cells from various

*Corresponding author: Shahbeigi Saeed, Shahid Beheshti Medical University Research Center, Tehran, Iran, E-mail: s_shahbeigi@yahoo.com

Received September 04, 2018; Accepted October 09, 2018; Published October 13, 2018

Citation: Saeed S, Soheila KR, Sima KR, Mandana MB, Hosein P, et al. (2018) A Comprehensive Review on the Application of Mesenchymal Stem Cell in the Treatment of ALS Patients. J Neurol Neurophysiol 9: 471. doi:10.4172/21559562.1000471

Copyright: @ 2018 Saeed S, et al. This is an open-access article distributed under the terms of the Creative Commons Attribution License, which permits unrestricted use, distribution, and reproduction in any medium, provided the original author and source are credited. 
tissues have shown to be CD34+ cells. It should be noticed that the expression of CD34 are exhibited more extensively on MSC isolated from other sources compared to BM, such as adipose tissue. Therefore it is more vastly accepted by researchers that CD34+ MSCs could be formed immediately following the extraction but quickly decrease in numbers after a short time in culture [12].

MSCs also express variable levels of CD44, stromal antigen-1, and a group of other adhesion molecules and receptors, including CD166 (vascular cell-adhesion molecule), CD54/CD102 (intracellular adhesion molecule), and CD49 (very late antigen). The variability in the expression of adult MSC surface markers could be related to different stages of culture [13].

\section{Application of MSCs in ALS Patients}

Inflammatory mediators like Tumor Necrosis Factor- $\alpha$ (TNF- $\alpha)$, interleukin- 1 beta (IL-1ß), IL-6 and IL-10 have a key role in pathogenesis of ALS $[14,15]$. It was found that the proinflammatory enzymes inducible Nitric Oxide Synthase (iNOS) and cyclooxygenase 2 (COX2) have been up-regulated in ALS patients and in the models $[16,17]$. The exact pathophysiology of ALS is still unknown. Animal studies have been designed for understanding the disease mechanism and also explore the MSC potential to treat this fatal disease.

The studies on MSCs effects in ALS patients, suggest indirect effects, including, the delivery of growth factors in situ, modulation of glial cells secretome, and up-regulating regulatory T-cell activity. Based on preclinical studies, MSC express 12 neural genes and 11 transcription factors, and also the ability to differentiate into neural and glial cells in an appropriate media [18]. As previously reported, MSC is able to modify expression of the neuroprotective chemokine fractalkine (CX3CL1) in glial cells lines [19].

The animal study which was conducted by Sun et al. [20] showed that MSC have neuroprotective role for motor neurons, microglia, astrocytes, and modifies their response to apoptosis which is managed by down-regulating expression of TNFa and IL-6 and iNOS. Uccelli et al. [21] found that paracrine mechanisms are more probable than the local production of growth factors. The co-culture of MSC with peripheral blood mononuclear cells which were derived from ALS patients, showed that the level of anti-inflammatory cytokines, including IL-4, IL-10 and Transforming Growth Factor beta (TGF- $\beta$ ) were up-regulated, and also regulatory $\mathrm{T}$-cell/total lymphocyte ratio were increased [22].

In a review published by Boruczkoski et al. [23], it was suggested that the effectiveness of MSCs in ameliorate ALS

Outcomes could be due to their ability to secret neurotrophic factors which play different roles in normal neural function and particularly in neural repair. The other possible treatment of ALS is the supplementation with factors like Glial cell line-Derived Neurotrophic Factor (GDNF), Vascular Endothelial Growth Factor (VEGF), ciliary neurotrophic factor, and Insulin-like Growth Factor 1 (IGF1) $[24,25]$. Several studies have demonstrated that MSCs can inhibit microglial activation and can reprogram microglial cells into an M2 like phenotype characterized by increased phagocytic activity and upregulated expression of anti-inflammatory mediators [26,27].

\section{Brain Storm NurOwn}

NurOwn cells are special mesenchymal stem cells which are grown in proper conditions for secreting varieties of NTFs [28]. Over 60 patients with Amyotrophic Lateral Sclerosis (ALS) have been treated with NurOwn ${ }^{\circledR}$ in clinical trials conducted in the United States and Israel, showing an excellent safety and tolerability profile, demonstrated promising signs of efficacy [29]. Assessment of, NurOwn (MSC-NTF) stem cells have been carried out in total 3 different phases and the results have been published [30,31]. The method of applying such brain storm cells in ALS patients involves intramuscularly injection in early stage of the disease and intrathecally in when it is progressed [30].

In a phase I double blind controlled trial conducted by Archia [32], patients with definite ALS were treated by MSCs-NTF. It was noticed a significant increase in VEGF, Hepatocytic Growth Factor (HGF), Lukemia Inhibitory Factor (LIF) in the treated group but not in the control group after 2 wks of the cells injection. The incident was correlated to lowering in inflammatory markers, such as Monocyte Chemoattractant protein 1 (MCP-1) and Stromal cell-Derived Factor 1 (SDF-1) in the group. It is anticipated that lowering in MCP-1 could be directly related to reduction in the disease progression. Also it was noticed that Chitotriosidase-1 (CHIT-1) was decreased in NurOwn treated patients, while slightly increased in the placebo group and explicated that a significant reduction of inflammatory factors in the CSF of treated group was observed.

\section{Methods for Selection of Studies from the Literature}

The literature search is conducted in Google scholar, PubMed, MEDLINE, clinicaltrials.gov in May 2018 using the following terms: Stem cell therapy, Stem cell and ALS, Mesenchymal stem cells and ALS in human, Mesenchymal stem cells and ALS. Those articles which are not focused on clinical features are excluded. The review on the clinical trials section includes the on-going published studies and also those studies which are published only as abstracts $[31,33]$ or in proceedings $[23,34,35]$. The review is only limited to those literatures published in English language and covers publications from 2003 to 2018.

\section{Clinical Trials}

\section{Efficiency trials}

A clinical trial was conducted by Mazzini [36] to analyze the safety and tolerability of MSCs injection in ALS patients. Seven ALS patients were injected 7-152x106 BM-MSCs intraspinaly at T7-T9 and then followed up for 6 years. The assessment showed no significant modification of the psychological status or QoL (Quality of Life). The trial manifested a trend towards slowing down of the linear decline of muscular strength in the proximal muscle groups of the lower limbs in 4 patients $(57.14 \%)$, but $2(28.58 \%)$ experienced only a mild increase.

In another study, nine spinal onset ALS patients were participated in Mazzini trial [37]. The patients were injected 32x106 autologous BM-MSCs by intraspinal infusion in different thoracic levels. It was reported, no structural changes of spinal cord were observed during 36 mon of the follow up. The study demonstrated a significant slowing down of the linear decline of Forced Vital Capacity (FVC) and ALS Functional Rating Scale (ALS-FRS) scores almost in 55.55\% of the patients $(n=5)$, suggesting the beneficial effects of stem cell therapy in ALS patients.

In another effort by Mazzini [38], nine ALS patients were injected $57 \times 106$ BM-MSCs intra spinally at different thoracic level and then followed-up for 48 mon thereafter. It was specified that a significant slowing down of the linear decline of the FVC and ALS-FRS scores in 4 participants $(44.44 \%)$ occurred. But only one patient experienced enhancing progression of the disease with no respiratory failure. It was noticed that no patient experienced negative reaction in their 
psychological wellbeing and abnormalities in their Magnetic Resonance Imaging (MRI) assessments and also in their Somatosensory Evoked Potentials (SSEPs). However, it was supported by four patients that the procedure was effective.

In the study by Karussis [39], autologous BM-MSCs were injected in 3 ALS patients both intravenously and intrathecal and then followedup for 1 mon and 11, 12 mon post treatment for each patient. The study demonstrated an initial significant improvement or stabilization in 2 patients $(66.66 \%)$ occurred for several mon after transplantation. Also, it was noted that beneficial effects of the treatment was mainly found on the leg muscle, because the injected cells could be reached more easily to the lower thoracolumbar parts of the spinal cord.

In a phase I clinical trial conducted by Mazzini [40], ten spinal onset ALS patients were injected 11-122 x 106 BM-MSCs at the high thoracic level (T4-T5, T5-T6) within 5-10 injection sites and then followed up for $24 \mathrm{mon}$. The clinical and instrumental measures: Motor Unit Number Estimation (MUNE) and Neurological Instrument (NI) showed no significant modification in declining or progression of the disease, and it did not reveal significant changes in the post treatment. It was also noticed that only 2 patients showed a slower deterioration of FVC and in the upper limb Medical Research Council (MRC) in 12 mon after transplantation rather than pre-treatment in the younger age. The QoL which was assessed by the Schedule for Evaluation of Individual Quality of Life-Direct Weighting (SEIQoLDW) in Minnesota Multiphasic Personality Inventory (MMPI) showed improvement in lead in period, but it linearly declined in 5 patients post treatment despite of stabilization in 5 of them. Cell doses and number of injection sites did not have any correlation to severity of side effects. This study suggests that those patients having spinal form of the disease and predominant lower motor neuron involvement also those with focal MND variant might benefit mostly from MSCs transplantation.

In an observational study which was conducted by Gamez [41], twelve ALS patients and 155 patients were enrolled as the main and the control groups, respectively. Three participants out of 12 were treated by $2 \times 106$ of fetal olfactory ensheating cells intracerebraly (cornea radiate), two were injected BM-MSCs intrathecally and intravenously and 7 were treated by stem cells rich in $\mathrm{CD} 34+$, intrathecally. The patients were followed up for median time of 20.2 mon post transplantation. It was found that from 5 patients who underwent Bilevel Positive Airway Pressure (BiPAP) at the mean time of 44 mon passing by onset of the disease, two of them required tracheostomy about 13 mon after transplantation. It was reported that the mean survival time of the patients from the onset to the end of the study was 50 mon. In comparison with the disease natural history, no change in the decline of FVC and ALS-FRS-R were observed in 9 patients who were treated by MSCs compared with the cohort group.

Karussis et al. [27] in 2010 enrolled 19 ALS patients to a 1/2 phase safety clinical trial. All the patients were injected $54.7 \times 106$ autologous BM-MSCs, intrathecally and also were injected intravenously $23.4 \mathrm{x}$ 106 cells in only 9 of them and then followed for 25 mon. It was noticed that during 6 mon follow up, the ALS-FRS score remained stable. An immediate immunomodulatory effect of MSCs was detected, including an increase in proportion of CD4-CD25 regulatory $\mathrm{T}$ cells (75\%) and reduction of the activated dendritic cells and lymphocytes proliferation (30-60\%), reduction in CD86, HLADR+, myeloid dendritic cells and CD40+, 4 hrs. after infusion. No major adverse events or significant unexpected pathology in their MRI were reported in the participants.

Mazzini et al. [42] examined the safety and efficacy of BM-MSCs in treatment of 19 ALS patients in two phase I clinical trials as prospective open pilot study ( $n=9$ and $n=10$, respectively). Different numbers of stem cells (mean: $62.63 \times 106$ ) were injected into dorsal part of spinal cord in level of T7-T9 in the first trial and T4-T6 in the second trial and continued the study for a long time (9 years). It was then claimed that, in ALS-FRS and FVC, variation was 10\% or less in 6 patients and remained stable for 2 and 3 patients till 74 and 30 mon, respectively. Also, it was noticed that the progression of the disease slowed down after transplantation over a long period with prolonged survival in 6 patients. The stabilization was anticipated to be related to prognostic factors, such as young age of the patients and also to the prevalence of lower motor neuron of disease and not to the treatment procedure. No deterioration in psychological status (POEM, SEIQoL-DW) except in one patient was noticed. It was deduced that for avoiding the negative reaction on mood and Qol, careful selection of the patients could be a crucial factor. No structural changes or tumor formation were reported in the trials.

In a case study conducted by Minguell [43], a 62 year old man with progressive ALS was enrolled in the trial $0.6 \times 106$ allogenic MSCs per $\mathrm{kg}$ were infused intrathecally (L3-4) and then followed up for 12 mon clinically and also 18 mon on call thereafter. It was noticed that the FVC value was continued to be constant value during the entire follow up period. ALS-FRS score exhibited an early improvement which was remained relatively constant during the 12 mon. It was noticed that there was a transient improvement in the right and left grips which was measured by Hand Held Dynamometry (HHD) score, while right grip value was always higher than that of the baseline score, although, a time dependents decrease in the left grip value was observed. The quality of life was remained stable and showed remarkable repossession. This study showed a slowdown of disease progression as well as important survival benefits.

Kim et al. [44] designed an open-label, single arm, investigatorinitiated clinical study in 2014, in which 37 patients with definite or probable ALS based on El Escorial were participated. They were treated with $1 \times 106$ BM-MSC cells/kg intrathecally twice every each mon. After 6 mon follow up, the patients were divided into two groups of responder $(n=19,51.35 \%)$ and non-responder $(n=18)$ according to the specified criteria. In this trial improvement or stability in ALSFRS-R is considered as responder. They noticed that the mean decrement in the Amyotrophic Lateral Sclerosis Functional Rating Scale-revised (ALSFRS-R) score was significantly smaller in the responder's group in the first 3 mon of the follow up extending during the next 3 mon follow up which was no longer statistically significant. The levels of VEGF, ANG, and TGF-b were significantly higher in the responders than in the nonresponders. It was then concluded that VEGF, Angiopoietin (ANG), and TGF-b levels in MSCs could be used as the potential biological markers to predict the effectiveness of autologous MSC therapy and to identify those patients who could optimally benefit from MSC treatment.

In another trial, Oh et al. (2015) [45] conducted an open-label phase I clinical trial on 7 ALS patients. The BM-MSCs were injected twice, using $1 \times 106$ cells per kg interathecally with 26 days intervals at the level of L2-4 followed up for the next 12 mon. The level of Il-10, TGF- $\beta$ (I, II and III) and IL- 6 were increased after the transplantation, while the Monocyte Chemoattractant Protein 1 (MCP-1) was decreased in CSF samples which only evaluated in two patients post transplantation, but noticed that the level of IL-10 and TGF-b increased in the peripheral blood mononuclear cells. Then the outcomes were reported as follows: ALSFRS-R in $71.42 \%$ of the patients $(n=5)$ did not decrease during the first six mon and increased in $28,58 \%(n=2)$ 
during the first 2 and 3 mon of the initial follow up and then remained stable. Overall, decreasing in the ALSFRS-R score within the 6-mon follow up period became more gradual than the lead-in period, and the ALSFRS-R scores remained stable for 6 mon after the initial injection of MSCs. The rate of deterioration of the Apple ALS rating scale (AALS) score in the initial follow-up period was found to be lower than the lead-in period. But it was noticed that there were no differences in FVC deterioration between the 4-mon follow up and the lead-in periods. It should also point out that Non-Invasive Ventilation (NIV) and tracheostomy were not required for any of the patients but only one Percutaneous Endoscopic Gastrostomy (PEG) administration was reported. The report showed that some transient and mild adverse events (the most frequent: pyrexia, pain, headache) were found in the patients $($ CTCAE $\leq 2)$.

The results of a phase I/II clinical trial in which 11 ALS patients were infused BM-MSCs intrathecally was reported by Czaplinski [34]. The study carried out by no adverse events or detrimental effects on neurological functions. The treatment was done by no beneficial effects on the mean rate of ALSFRS in all patients but a significant decrease in the mean rate of change in ALSFRS in responder group $(n=7)$ were observed during the first 4-6 mon, suggesting a need of repeated transplantation.

Ten ALS patients as the main group and fifteen as the control group were enrolled in a clinical trial which was designed by Rushkevich [46]. 42-102 $\times 106$ fresh MSCs were injected intravenously at first and at the end of 6-7 days, 5-9.7 x 106 neural induced MSC were administrated via lumbar puncture (L3-L4). 6 patients received one course and the other 4 received 2 courses of intervention at 5-7 mon interval. The follow up period after transplantation was about $12 \mathrm{mon}$. The results of the study were reported as follows: ALSFRS-R, 34 in the main group and 16 in the control group, Karnofsky, 70\% in the main group and $20 \%$ in the control group, Quotient of disease Progression Rate (QPR); significantly lower in the process of declination in the main group (ALSFRS-R:0.38 vs. 1.47, Karnofsky:0.83 vs. 3.07). Three patients in the main and all in the control group showed involvement of bulbar muscles in 9 mon of the follow up. The study demonstrated that two and five death occurred in the main and the control group, respectively. As the conclusion, it was reported that a slowdown of progression and delay of the development of bulbar, pseudobulbar and respiratory status in treated patients were occurred which improved the QoL.

Staff et al. [47] clinically studied 27 patients with diagnosis of ALS in a phase I dose-escalation safety trial in 2016. The patients were divided into five groups and were injected, intrathecally with different doses of adipose derived MSCs in different times group $1(n=5): 1$ x 107 cell, single dose; group $2(n=5): 5 \times 107$, single dose; group 3 $(\mathrm{n}=7)$ : 5 x 107, 2 mon injection; group $4(\mathrm{n}=5): 1 \times 108$, single dose and group $5(n=5): 1 \times 108,2$ mon injection and then followed for 2 yrs. No differences were observed in ALSFRS progression before and after injections. The study reported that 17 patients experienced mild transient subjective improvement, such as bulbar function $(n=8)$, limb strength $(n=5)$, decreased fasciculation $(n=4)$, decrease stiffness $(n=4)$ and improved energy $(n=4)$ which were not considered as a positive treatment response. Transient changes in CSF parameters and stable dose dependent changes in MRI were also reported, it means that it was no increase in the number of monocytes was observed and then their number began to decrease to wk 4 . On the other hand, glucose level decreased, but no abnormal of OCB was reported to wk 4 of their study and, no tumor formation and severe adverse events were observed. Only some temporary low back and radicular leg pains were reported in the high doses of cell $(\mathrm{n}=8$ from $\mathrm{n}=10)$. Lumbosacral nerve root thickening with clumping and gadolinium enhancement was indicating that arachnoiditis increased in severity with the increase of dose level.

A study conducted on Wharton's jelly-derived MSC (from healthy new born) and ALS by Boruczkowski [48]. Seventeen ALS patients enrolled in the study which was divided into 3 groups: 9 patients infused IT, 1 infused IV, 7 infused first IT and then IV. The IT injection dose was $30 \times 106$ per infusion and IV was $1.17 \times 106 / \mathrm{kg} /$ infusion. Each patient received 1-7 (mean: 2 ) infusion within 4-8 wks interval. Only minor adverse side effects were reported in the patients. Seven of the participant showed improvement in neurological examination, such as muscle tension and strength and six showed stability in their neurological status. The clinical condition was deteriorated in 3 patients who may attribute to either disease progression or administration of the stem cells.

In a prospective, nonrandomized, open-label clinical trial which was conducted by Sykova et al. [49], twenty six ALS patients were treated with BM-MSCs with a single dose of $15 \pm 4.5 \times 106$ intrathecally followed for 18 mon post treatment. The safety was studied in all participants and the efficacy of treatment was assessed in 23 of them. ALSFRS score decline showed a reduction or stabilization at 3 mon after transplantation which persisted in some cases for 6 mon. The patients based on pre-transplantation progression, were divided into 2 groups. Analysis of the results showed slowdown of progression in 3, $6,9,12$ mon after transplantation in patients who showed a decline of 2-6 scores in ALS-FRSR and was not recorded in the stable ones. The study also suggested that the FVC value remained stable or above $70 \%$ in about 80 mon \& of the participants which remained intact for 9 mon and for 112 mon in $60 \%$. Also the Weakness Scale (WS) remained stable in almost $75 \%$ of the patients at 3 mon after the cell delivery and started to decrease at 12 mon of the follow up. It was then suggested that WS and FVC were more reliable than ALSFRS, argued that ALSFRS is a subjective score and was more influenced by the patient mental status. No suspected or $v s$. AE (adverse event) or new intradural cerebrospinal pathology in MRI findings was reported.

In a study which was presented by Gabri et al. [35]. Ten ALS patients as the treatment group and 5 patients as the control were enrolled. The treatment group was injected $2 \times 106 / \mathrm{kg}$ BM-MSCs intrathecally and repeated every mon for 6 mon follow up. Despite of 2 patients in the control group, no deterioration in the treatment group was observed. It was noticed that the main group experienced an improvement in the ALSFRS scale, Mann Assessment of Swallowing ability (MASA), 40item ALS, Assessment Questionnaire (ALS-AQ-40) and FVC, 80\%, $70 \%, 80 \%$ and $50 \%$ of the patients, respectively.

According to Petrou [30], twenty six patients with ALS were enrolled and treated with BM-MSC secreting neurotrophic factor (BM-MSC-NTF). The study was divided into two phases: 1) On the $1 / 2$ phase, 12 patients were enrolled, in which, half of them was given $1 \times 106$ cells/site MSC-NTF as 24 injections directly at the biceps and triceps muscles. The rest were given MSC-NTF as 106 cells per kg intrathecally. 2) On the phase 2a, 14 patients received MSC-NFT by combination of IM and IT injections as dose escalating. The escalating doses were as follows: low dose $(\mathrm{n}=4) ; 106 / \mathrm{kg}$ IT and $24 \times 106 \mathrm{IM}$, medium dose $(\mathrm{n}=6) ; 1.5 \times 106 / \mathrm{kg}$ IT and $36 \times 106$ IM, high dose $(\mathrm{n}=4) ; 2 \times 106$ IT and $48 \times 106$ IM. Considering that the improvement of ALSFRS-R and FVC were observed in IT groups, the analysis was limited on IT and IT+IM groups in the whole study. At 3 mon of follow-up ( $n=18), 78 \%$ $(n=14)$ were the responders, and among those who were followed up for 6 mon $(n=15), 87 \%(n=13)$ were the responders. Six mon after the 
treatment, $80 \%(\mathrm{n}=12)$ of the patients improved by more than $35 \%$ and $67 \%(n=10)$ by more than $50 \%$ to either ALSFRS-R score or FVC. The responders were defined in the study as those who's ALSFRS-R or FVC were improved about 25 in comparison with pre-treatment state. In addition, Compound Muscle Action Potentials (CMAPs) and muscular volume were improved specially at the injected site showing the local neurotrophic effects. Also, an upregulation of CD4+ and CD25+ post treatment was observed. In safety assessment of the trials, except a nephrolithiasis which was unrelated to the treatment, no serious adverse events were observed.

Kern et al. [31] conducted a phase II, multi-center, randomized, double blind, placebo controlled trial in 2018 to study the effects of MSC-NTF on ALSFRS-R subscales domains. Forty eight participants (3:1 Active, Placebo) were enrolled and followed up their responses for 6 mon after a single administration of MSC-NTF (IT and IM injection). A higher percentage of the patients showed improvement more or equal than 1.5 point/mon in total of ALSFRS-R at 4 and 12 wks. Such improvement was more evident in the sub group that excluded slow progression (pretreatment changes ALSFRS- $\mathrm{R} \geq-2.5$ ). This improvement was particularly in bulbar (4 wk, 47\%; $8 \mathrm{wk}, 47 \%$; $12 \mathrm{wk}, 40 \% ; 24 \mathrm{wk}, 40 \%$ ) and fine motor ( $2 \mathrm{wks}, 87 \%$ ). This finding was also reported in gross motor and breathing domain which was not significant. In this study $\geq 0.375$ point/mon improvement in each four subscales consider as response. Summary of the trials are listed in Tables $1 \& 2$.

\section{Summary and Conclusion}

This review attempts to collect broad authentic scientific information about the history of the trend of ALS in world population and the most and least affected areas in the world in the future. However, there is some controversy around the development, usage of stem cells including MSCs. Randomized Control Trial (RCTs) with placebo controls is considered as the gold standard for clinical investigation [50]. The highest number of patients $(n=48)$ in the trial belongs to the study performed by Kern et al. [31], while the least belongs to Minguel et al. [43] and Baek et al. [33] one each. In the clinical trials, different scales including ALSFRS(R), FVC, MRI, electrophysiology (EEG, SSEPs, etc), psychology and quality of life Beck Hopelessness Scale (BHS), Depression Inventory-12 (ADI-12), Minnesota Multiphasic Personality Inventory (MMPI), European Quality of Life (EuroQol), The Schedule for the Evaluation of the Individual Quality of Life-Direct Weighting (SELQOL-DW), etc. were assessed. In the current review, the efficacy of such stem cell therapy is evaluated by ALSFRS (R), FVC and muscle strength [41]. Clinical trials assessed 325 ALS patients and 187 control group patients. In all the reported trials, except 2 [47], Boruczkowski in

\begin{tabular}{|c|c|c|c|c|c|c|c|}
\hline Rank & Author & Year & No. patients/control & Cell Product & Cell Number & Route & Infusion Rate \\
\hline 1 & Mazzini et al. [36] & 2003 & 7 & A-BM-MSCsa & $7-152 \times 10^{6}$ & IS & single \\
\hline 2 & Mazzini et al. [37] & 2006 & 9 & A-BM-MSCs & $32 \times 10^{6}$ & IS & Single \\
\hline 3 & Mazzini et al. [38] & 2008 & 9 & A-BM-MSCs & $57 \times 10^{6}$ & IS & single \\
\hline 4 & Karussis et al. [39] & 2008 & 3 & A-BM-MSCs & NM & $\mathrm{IT}+\mathrm{IV}$ & Single \\
\hline 5 & Mazzini et al. [40] & 2010 & 10 & A-BM-MSCs & $75 \times 10^{6}$ & IS & Single \\
\hline 6 & Gamez et al. [41] & 2010 & 9/155 & A-BM-MSCs & NM & $I T+I V / I T$ & Single \\
\hline 7 & Karussis et al. [27] & 2010 & 19 & A-BM-MSCs & $\begin{array}{l}\text { IT: } 54.7 \times 10^{6} \\
\text { IV: } 23.4 \times 10^{6}\end{array}$ & $\mathrm{IT} / \mathrm{IT}+\mathrm{IV}$ & Single \\
\hline 8 & Mazzini et al. [42] & 2012 & 19 & A-BM-MSCs & $62.63 \times 10^{6}$ & IS & Single \\
\hline 9 & Minguell et al. [43] & 2013 & 1 & Allogenic-MSCs & $0.6 \times 10^{6} / \mathrm{kg}$ & IT & single \\
\hline 10 & Kim et al. [44] & 2014 & 37 & A-BM-MSCs & $1 \times 10^{6} / \mathrm{kg}$ & IT & Twice \\
\hline 11 & Oh et al. [45] & 2015 & 7 & A-BM-MSCs & $1 \times 10^{6} / \mathrm{kg}$ & IT & Twice \\
\hline 12 & $\begin{array}{c}\text { Czaplinski A et al. } \\
{[34]}\end{array}$ & 2015 & 11 & A-BM-MSCs & NM & IT & Single \\
\hline 13 & Rushkevich et al. [46] & 2015 & $10 / 15$ & $\begin{array}{l}\text { Neural induced- } \\
\text { MSCs }\end{array}$ & $\begin{array}{l}\text { IV: } 72 \times 10^{6} \\
\text { IT: } 7.35 \times 10^{6}\end{array}$ & $I V+I T$ & $\begin{array}{l}\text { Single }(n=6) \\
\text { Twice }(n=4)\end{array}$ \\
\hline 14 & Staff et al. [47] & 2016 & 27 & AD-MSCs & $\begin{array}{l}\text { Group1: } 1 \times 10^{7} \\
\text { Group2: } 5 \times 10^{7} \\
\text { Group3: } 5 \times 10^{7} \\
\text { Group4: } 1 \times 10^{8} \\
\text { Group5: } 1 \times 10^{8}\end{array}$ & IT & $\begin{array}{l}\text { Group1: single } \\
\text { Group2: single } \\
\text { Group3: twice } \\
\text { Group4: single } \\
\text { Group 5: twice }\end{array}$ \\
\hline 15 & $\begin{array}{l}\text { Boruczkowski et al. } \\
{[23]}\end{array}$ & 2016 & 17 & Wj-MSCs & $\begin{array}{c}\text { IT: } 30 \times 10^{6} \\
\text { IV: } 1.17 \times 10^{6} / \mathrm{kg}\end{array}$ & IT/ IV/ IT+IV & Mean: twice \\
\hline 16 & Petrou et al. [30] & 2016 & 26 & A-BM-MSCS-NTF & $\begin{array}{c}\text { Phase I: } \\
\text { IM: } 1 \times 10^{6} / \text { site } \\
\text { IT: } 1 \times 10^{6} / \mathrm{kg} \\
\text { Phase } 2 \mathrm{a}: \\
\text { Group1: } 1 \times 10^{6} / \mathrm{kg} \\
\text { IT+24 } \times 10^{6} \mathrm{IM} \\
\text { Group2: } \\
1.5 \times 10^{6} / \mathrm{kg} \mathrm{IT}+36 \times \\
10^{6} \mathrm{IM} \\
\text { Group3: } 2 \times 10^{6} / \mathrm{kg} \\
\text { IT+48 } \times 10^{6} \mathrm{IM}\end{array}$ & $\begin{array}{c}\text { Phase I: IM/IT } \\
\text { Phase 2a: IM+IT }\end{array}$ & Single \\
\hline 17 & Sykova et al. [60] & 2017 & 26 & A-BM-MSCs & $15 \pm 4.5 \times 10^{6}$ & IT & Single \\
\hline 18 & Gabr et al. [35] & 2017 & $10 / 5$ & A-BM-MSCs & $2 \times 10^{6} / \mathrm{kg}$ & IT & 6 \\
\hline 19 & Kern et al. [31] & 2018 & $36 / 12$ & A-BM-MSCs-NTF & NM & $\mathrm{IM}+\mathrm{IT}$ & Once \\
\hline
\end{tabular}

Note: a. A-BM-MSCs: Autologous bone marrow derived mesenchymal stem cells.

Table 1: Different cell products and infusion routes, rate in different trials. 


\begin{tabular}{|c|c|c|c|c|c|}
\hline Rank & Authors & year & No. $^{a}$ & Follow up (months) & Promising result ${ }^{\mathrm{b}}$ (percentage) \\
\hline 1 & Mazzini et al. [36] & 2003 & 7 & 72 & 75.14 \\
\hline 2 & Mazzini et al. [37] & 2006 & 9 & 36 & 55.6 \\
\hline 3 & Mazzini et al. [38] & 2008 & 9 & 48 & 44.44 \\
\hline 4 & Karussis et al. [39] & 2008 & 3 & 12 & 66.7 \\
\hline 5 & Mazzini et al. [40] & 2010 & 10 & 12 & $20^{\circ}$ \\
\hline 6 & Gamez et al. [41] & 2010 & 9 & 20.2 & 0 \\
\hline 7 & Karussis et al. [39] & 2010 & 19 & 6 & 100 \\
\hline 8 & Mazzini et al. [40] & 2012 & 19 & 108 & 31.58 \\
\hline 9 & Minguell et al. [43] & 2013 & 1 & 30 & Good achieved \\
\hline 10 & Kim et al. [44] & 2014 & 37 & 6 & 51.35 \\
\hline 11 & Oh et al. [45] & 2015 & 7 & 12 & 100 \\
\hline 12 & Czaplinski et al. [34] & 2015 & 11 & 6 & 63.64 \\
\hline 13 & Rushkevich et al. [46] & 2015 & 10 & 12 & 100 \\
\hline 14 & Staff et al. [47] & 2016 & 27 & 24 & 62.96 \\
\hline 15 & Boruczkowski et al. [23] & 2016 & 17 & NM & 74.47 \\
\hline 16 & Sykova et al. [60] & 2017 & 26 & 18 & 80 \\
\hline 17 & Gabr et al. [35] & 10 & 6 & 6 & 100 \\
\hline 18 & Petrou et al. [30] & 2016 & 26 & 6 & 80 \\
\hline 19 & Kern et al. [31] & 2018 & 36 & 36 & Majority \\
\hline
\end{tabular}

Note: a. Only treated groups are mentioned; b. Improvement or stability in ALSFRS(R) and/or FVC and/or MRC are considered as the promising result; c. It is important to note that the author did not mention any promising result in 24 months of follow up.

Table 2: Clinical trials promising outcome.

a conference [48], autologous MSCs were applied and 2 were focused on novel NurOwn brainstorm [27,30,31]. Among the published research articles with an aim of MSCs therapy on ALS patients, we identified some similarities and differences in both methods and the published results [49-53].

\section{Safety of MSC therapy in ALS}

Three research articles have only emphasized on the safety of the treatment $[33,54,55]$, while 19 studies focused both on safety and the efficacy, among which eight of them have concentrated more on the safety aspect of the treatment $[27,36,40,45,47,55-57]$. The trials have not reported any SAE and structural changes or tumor formation in the MRI findings, but mild and transient complications (CTCAE $\leq 2)$ are reported which do not relate to the cell therapy. The IV, IT, IM, IS administration routes in the trials, as reported in the literatures were safe and well tolerated.

\section{Efficacy of MSC therapy in ALS}

The successful administration of stem cells critically depends on their transplantation at the optimal stage of the disease course. As listed in Table 2, most of the studies reported promising results, which included improvement or stabilization in the course of the disease. The most efficacies belong to Karussis et al. [27], and Rushkevich et al. [46], Gabri et al. studies (100\% of the patients). The methods administrated in their studies are as follows:

- Karussis et al. [47] injected MSCs via combination of IV and IT. The Stem Cells (SCs) via intrathecal injection can circulate with the flow of the CSF and have a good chance to reach the affected CNS. However, the optimal route suggested of stem cell delivery in literature-and specially MSC administration-in clinical trials including neurological diseases remains debatable. Some other researchers have claimed that IV injection probably is sufficient and equally effective. This is because MSCs can migrate through the blood to the damaged areas of the CNS after receiving inflammatory signals due to the peripheral immune modulating effects [56-58] which has reviewed by Martino [59]. However, despite many advantages reported for carry out this method of administration, some disadvantages also have been reported which are listed in Table 3. The present review suggests that cell therapy with combined administration (intravenous and intralumbar) of

- Autologous MSC to patients with ALS is a safe treatment that helped to slow down the disease progression. Forostyak et al. [60] showed that intrathecal and intravenous transplantation of MSCs had a beneficial and probably synergistic effect on the lifespan of ALS rodents.

- In these four trials, MSCs were injected intrathecally in lumbar site.

- Fresh MSCs with 2-3 passages ( $\mathrm{n}=42-102 \times 106$ (IV); 5-9.7 x 106 (IT)) were used in Rushkevich trial [61].

\section{Follow up}

Stem cell therapy requires careful patient monitoring and extended follow-up. Long-term follow-up must consider the possibility of development of tumors, cyst, or syrinx at the site of transplantation (safety) or persistence of the efficacy. For instance, Sykova et al. [49], finds that the benefits effect of the therapy which is observed in 3 mon of follow up, persists only in some cases after 6 mon. Among all the studies, the longest followed-up duration was 12 years which carried out by Fagioli et al. [55] who focused on safety, and followed by Mazzini et al. [56] with 9 years follow up.

\section{Source of MSCs}

Although most of the sources of collecting MSCs are from BM, but two sources are adipose derived [47] and Wharton jelly [48]. It is claimed that such cells could also be extracted from amniotic fluid which have more advantages that the other sources. 
Citation: Saeed S, Soheila KR, Sima KR, Mandana MB, Hosein P, et al. (2018) A Comprehensive Review on the Application of Mesenchymal Stem Cell in the Treatment of ALS Patients. J Neurol Neurophysiol 9: 471. doi:10.4172/2155-9562.1000471

Page 7 of 18

\begin{tabular}{|c|c|}
\hline Advantages & Disadvantages \\
\hline \multicolumn{2}{|c|}{ Intraspinal (IS) } \\
\hline $\begin{array}{l}\text { - Well Migration to the ventral horn and were located in close proximity to MNs. } \\
\text {-Allow for accurate and reliable delivery that can be easily scaled up to human. } \\
\text {-Delivers stem cells directly to the area of pathology and do not require systemic } \\
\text { migration. } \\
\text {-Reducing the risk of adverse effects. } \\
\text {-Reducing the number of cell required. } \\
\text {-High engraftment efficiency. } \\
\text {-High chance to differentiation. } \\
\text {-Cross the blood-brain barrier which is intact in ALS. }\end{array}$ & $\begin{array}{l}\text {-Has not resulted in significant safety issues in clinical study concern regarding } \\
\text { potential surgical damages to the disease area and the increasing evidence for } \\
\text { non replacement mechanisms of MSC repair. } \\
\text { - Carries the addition risk of manipulation of spinal cord pathology. } \\
\text {-Multiple injections are needed. } \\
\text {-Require multilevel laminectomy and opening of the dura matter. } \\
\text { - The unsteady needle can move and sheer white matter tracts. } \\
\text {-The uncontrolled rate of injection promotes reflux of the therapeutic agent up the } \\
\text { cannula track and increase the risk for spinal cord mass effected by elevated intra- } \\
\text { parenchymal pressure. } \\
\text {-Limited efficacy because neuron degeneration is widespread along the spinal } \\
\text { cord, brain and brain stem. } \\
\text {-Risk of direct trauma to the spinal cord parenchyma. }\end{array}$ \\
\hline \multicolumn{2}{|c|}{ Intracereberoventricular (ICV) } \\
\hline $\begin{array}{l}\text {-Similar effects compared with spinal transplantation. } \\
\text {-Neuroprotective factors released by the cell directly reach the whole spinal cord and } \\
\text { brain via CSF. } \\
\text {-Reducing the risk of adverse effects. } \\
\text {-Reducing the number of cell required. }\end{array}$ & $\begin{array}{l}\text {-Avoid direct intervention in the affected region of the spinal cord. } \\
\text {-Require surgical procedure. }\end{array}$ \\
\hline \multicolumn{2}{|c|}{ Intramuscular (IM) } \\
\hline $\begin{array}{l}\text {-Avoid complication related to surgery and can take advantages of the plasticity of } \\
\text { MSC. } \\
\text {-Proximity to the affected area without requiring direct intervention in to the CNS. } \\
\text {-Effective trophic factor delivery technique in rodents. }\end{array}$ & $\begin{array}{l}\text {-Less efficient than CNS delivery. } \\
\text {-Require greater doses for results comparable to those of direct delivery. }\end{array}$ \\
\hline \multicolumn{2}{|l|}{$\begin{array}{ll} & \text { Intravenous (IV) }\end{array}$} \\
\hline $\begin{array}{l}\text {-Significant improve disease measures in rodent ALS models. } \\
\text {-Reduce microglia activation and reduce oxidative stress as potential mechanism of } \\
\text { repairement. } \\
\text {-Safe and easy in ALS patients. } \\
\text {-Possibility of multiple injections. } \\
\text {-MSCs exert peripheral immunomodulatory effects and may also migrate through the } \\
\text { blood to the damaged areas of the CNS after receiving inflammatory signals. } \\
\text {-Reducing the risk of adverse effects. }\end{array}$ & $\begin{array}{l}\text {-Cell migration to various peripheral tissues as well as to the brain and spinal cord. } \\
\text {-Rely on the stem cell's ability to migrate to the local areas of pathology. } \\
\text {-No migration into the spinal cord parenchyma } \\
\text { - -Having high Risk of cell loss during circulation due to setting of infused cells in } \\
\text { many peripheral tissues, such as lung, liver or spleen. } \\
\text {-Need high number of cells. } \\
\text { - Mutation in cells. } \\
\text {-Most of the cells injected to the blood will home to the lung, lymph nodes and } \\
\text { other tissues, reducing the number of cell available to migrate to the CNS. } \\
\text {-Very poor engraftment of efficiency. }\end{array}$ \\
\hline \multicolumn{2}{|r|}{ Intrathecal (IT) } \\
\hline $\begin{array}{l}\text {-Increase the possibility of migration of the injected cells to the proximity of the CNS } \\
\text { lesion. } \\
\text {-The injected cells may circulate with the flow of the CSF and have a better chance } \\
\text { of reaching the affected CNS area. } \\
\text {-Induce superior neurotrophic and neuroprotective effects. } \\
\text {-May focus their possible immunomodulatory and trophic effect directly on the CNS } \\
\text { without producing systemic adverse effect. } \\
\text {-Safer, less invasive and easier to perform than intra-spinal (rev by cievro). } \\
\text {-Bypass BBB obstacle. } \\
\text {-Possibility of multiple injections. } \\
\text {-Greater number of cells can reach the CNS tissue without being trapped in the lung } \\
\text { or other organs. } \\
\text { - ALS induces widespread degeneration throughout the length of the neural axis, the } \\
\text { intrathecal approach may be more likely to influence multiple affected regions in the } \\
\text { brain and the spinal cord because of the dynamics of CSF flow. } \\
\text {-Reduce the likelihood of the injected MSC becoming trapped in the lung when } \\
\text { compared with intravenous administration. }\end{array}$ & $\begin{array}{l}\text {-Rely on the stem cell ability to migrate to the local area of pathology. } \\
\text {-Dose dependent migration of mesenchymal stem cells in to the brain and spinal } \\
\text { cord. } \\
\text {-Direct application to the spinal cord parenchyma is invasive. } \\
\text { A small percentage of intrathecal injected cells also migrate to the spinal cord } \\
\text { parenchyma and ventricles. } \\
\text {-Low chance of differentiation. }\end{array}$ \\
\hline
\end{tabular}

Table 3: Type of MSCs transplantation: disadvantages and advantages.

\section{Ongoing trials}

All the clinical trials have been registered in PubMed ("clinicaltrials. gov') and for obtaining the information cited in the on-going articles, "ALS" and "MSCs" keywords have been used. In our searches, 16 ongoing clinical trials have been found, two of which were withdrawn by Iranian authors. The completion dates of one of the as recorded in the data base was 2011, two on 2014, one on 2015, two on 2017, three on 2018 , four on 2019 , and one on 2021 . The most ongoing researches on the application of MSC on ALS (4 studies) belongs to USA. Bone marrow and Adipose, at the same level $(n=6)$, are the most common sources for stem cell therapy compared with the others in the ongoing trials. It is found that intrathecal administration with the frequency of 10 , is the most common method of administration and the other methods are as follows: three IV, one IS+IT, one IS and one and one intraventricular. Seven of the studies have clearly explicated the cell dosage using in the trial. Three of the trials used single infusions and nine used multiple in different groups, but the rest have not determined the exact time of the infusion. In the ongoing studies, only 2 trials used placebo in their studies. One trial was designed as a double blind trial, one triple blind and the rest conducted their trials as an open label. From the beginning to the end (2021) of the ongoing trials, 510 ALS patients will be assessed and among which, 415 will be treated intrathecally. On the basis of advantages of NurOwn, one trial plans to administer NurOwn in the phase III clinical trial. The 
Citation: Saeed S, Soheila KR, Sima KR, Mandana MB, Hosein P, et al. (2018) A Comprehensive Review on the Application of Mesenchymal Stem Cell in the Treatment of ALS Patients. J Neurol Neurophysiol 9: 471. doi:10.4172/2155-9562.1000471

Page 8 of 18

inclusion criteria of all the ongoing studies have been clearly stated. Table 4 depicted the register and ongoing clinical trials focusing to study the effect of MSCs in ALS patients.

\section{Acknowledgment}

We would like to thank Prof. Dr. Mansoor Kianpour Rad for English proof reading of our manuscript.

\begin{tabular}{|c|c|c|c|c|c|c|c|c|c|c|c|c|c|c|}
\hline NCT & Age & $\begin{array}{c}\text { Completion } \\
\text { date }\end{array}$ & Country & Intervention & Patient & Control & Phase & Route & Dose & Time & Masking & ALSFRS & FVC & Out-comes \\
\hline 02492516 & $18-55$ & Apr. 2017 & Iran & $\begin{array}{c}\text { AD- } \\
\text { MSC(Allogenic) } \\
\end{array}$ & 19 & NO & 1 & IV & $\begin{array}{l}2 \times 10^{6} \\
\text { cells } / \mathrm{kg}\end{array}$ & single & $\mathrm{OL}$ & $>24$ & $>40 \%$ & $\begin{array}{c}\text { ALSFRS, FVC, electromyography, } \\
\text { selogic test }\end{array}$ \\
\hline 03268603 & $\geq 18$ & Dec. 2019 & USA & AAD-MSC & 60 & NO & II & IT & $1 \times 10^{8}$ & $\begin{array}{c}4 \text { every } 3 \\
\text { months }\end{array}$ & OL & NM & NM & AE, ALS-FRS-R \\
\hline 02290886 & $\geq 18$ & Feb. 2021 & Spain & AAD-MSC & 40 & YES & $|-| \mid$ & IV & $\begin{array}{l}1 \times 10^{6} \\
\text { cells } / \mathrm{kg} \\
2 \times 10^{6} \\
\text { cells } / \mathrm{kg} \\
4 \times 10^{6} \\
\text { cells } / \mathrm{kg}\end{array}$ & single & $\begin{array}{l}\text { Triple } \\
\text { blind }\end{array}$ & NM & $>50 \%$ & $\begin{array}{l}\text { SUSSARS, SAE, ALS-FRS-R, } \\
\text { MRC, FVC, NMR, QoL, } \\
\text { Neurological parameters, Need } \\
\text { and time to tracheostomy or } \\
\text { permanent assisted ventilation, } \\
\text { Complication in the place of the } \\
\text { infusion, New neurological effects } \\
\text { not to attributed to the neural } \\
\text { progression of the pathology }\end{array}$ \\
\hline 03296501 & $18-65$ & Oct. 2019 & Poland & AADRC & 30 & NO & 1 & IS (1)+I (2) & NM & $\begin{array}{c}3 \text { every } 3 \\
\text { months }\end{array}$ & $\mathrm{OL}$ & NM & - & $\begin{array}{c}\text { ALS-FRS-R, FVC, EMG, } \\
\text { MUNIX, neuroimaging, } \\
\text { Electrophysiography, MRC, } \\
\text { Dynamometry }\end{array}$ \\
\hline 01759784 & $18-70$ & Null & Iran & ABM-MSC & 0 & NO & 1 & Intraventricular & NM & NM & OL & $>26$ & $>40 \%$ & AE, ALS-FRS, EMG-NCV, FVC \\
\hline 02116634 & $18-60$ & May. 2017 & Iran & ABM-MSC & 0 & NO & $\mid-I I$ & IS & $1 \times 10^{8}$ & NM & $\mathrm{OL}$ & $\begin{array}{l}\geq 50 \% \text { of } \\
\text { predicted }\end{array}$ & $\begin{array}{l}\geq 50 \% \text { of } \\
\text { predicted }\end{array}$ & $\begin{array}{c}\text { DWSE } \pm \text { QoL, FVC, ALSFRS, } \\
\text { EMG }\end{array}$ \\
\hline 01759797 & $18-65$ & Mar. 2014 & Iran & ABM-MSC & 6 & NO & 1 & IV & NM & NM & OL & $>26$ & $>40 \%$ & AE, ALS-FRS, FVC, EMG-NCV \\
\hline 01771640 & $18-65$ & Dec. 2014 & Iran & ABM-MSC & 8 & NO & $\mathrm{I}$ & IT & NM & NM & OL & $>26$ & $>40 \%$ & AE, ALS-FRS, FVC \\
\hline 02917681 & $18-70$ & Aug. 2019 & Brazil & ABM-MSC & 28 & NO & $|-| \mid$ & IT & NM & $\begin{array}{l}2 \text { every } \\
\text { one } \\
\text { month }\end{array}$ & OL & $\begin{array}{l}\text { ALS- } \\
\text { FRS-R } \\
\geq 30\end{array}$ & FVC $>65 \%$ & $\begin{array}{l}\text { AE, ALSFRS-R, HHD, Electrical } \\
\text { Impedance Myography, FVC, } \\
\text { Isometric Strength, BMRI, SMRI }\end{array}$ \\
\hline 02881489 & $18-65$ & Dec. 2018 & Poland & ABM-MSC & 30 & NO & I & IT & NM & $\begin{array}{l}\text { Single } \\
\text { in one } \\
\text { group } \\
\text { Three } \\
\text { every two } \\
\text { month } \\
\text { in other } \\
\text { group }\end{array}$ & $\mathrm{OL}$ & NM & $>50 \%$ & ALSFRS, EMG, FVC,AE \\
\hline 02881476 & $18-65$ & Dec. 2018 & Poland & $\begin{array}{c}\text { Wj- } \\
\text { MSC(allogenic) }\end{array}$ & 30 & NO & 1 & IT & NM & $\begin{array}{c}\text { Single } \\
\text { in one } \\
\text { group } \\
\text { Three } \\
\text { every two } \\
\text { month } \\
\text { in other } \\
\text { group }\end{array}$ & $\mathrm{OL}$ & NM & $>50 \%$ & ALSFRS, EMG, FVC, AE \\
\hline 01494480 & $20-65$ & Apr. 2015 & China & $\begin{array}{l}\text { UC-MSC } \\
\text { (allogenic) }\end{array}$ & 30 & NO & ॥ & IT & NM & $\begin{array}{l}4 \text { every } \\
3-5 \text { days }\end{array}$ & $\mathrm{OL}$ & NM & $\geq 50 \%$ & $\begin{array}{l}\text { Nerve functional evaluation, } \\
\text { FVC, Blood test, Urinal test, } \\
\text { Electrophysiology, EMG, MEP, } \\
\text { PEF. FEV1, FEV1/FVC, MVV, } \\
\text { MMSE, BDI, Elis reflex scale, } \\
\text { Norris, BDI }\end{array}$ \\
\hline 01609283 & $\geq 18$ & Apr. 2018 & USA & AAD-MSC & 25 & NO & 1 & IT & $\begin{array}{l}\text { G1: } 1 \times 10^{7} \\
\text { G2: } 5 \times 10^{7} \\
\text { G3: } 5 \times 10^{7} \\
\text { G4: } 1 \times 10^{8} \\
\text { G5: } 1 \times 10^{8}\end{array}$ & $\begin{array}{c}\text { Group } \\
1,2 \text { and } 4: \\
\text { single } \\
\\
\text { Group } \\
3,5 \text { : twice } \\
\text { separated } \\
1 \text { month }\end{array}$ & $\mathrm{OL}$ & NM & $>65 \%$ & $\begin{array}{l}\text { Number of patients with dose- } \\
\text { limiting toxicities, Number } \\
\text { of patients with AE, serum } \\
\text { sedimentation rate, CRP levels, } \\
\text { CBC, total nucleated cell count } \\
\text { in CSF, protein level in CSF, } \\
\text { Number of patients with presence } \\
\text { of cancer cells in their CSF }\end{array}$ \\
\hline 01142856 & $\geq 18$ & Apr. 2011 & USA & AAD-MSC & 1 & NO & 1 & IT & $1 \times 10^{6}$ & single & $\mathrm{OL}$ & NM & NM & Safety, Neurologic disability score \\
\hline 02987413 & $\geq 18$ & Apr. 2017 & Brazil & MSC & 3 & NO & 1 & IT & $1 \times 10^{8}$ & $\begin{array}{c}\text { Twice } \\
\text { every } 30 \\
\text { days }\end{array}$ & $\mathrm{OL}$ & NM & NM & $\begin{array}{l}\text { SAE, ALSFRS-R, QoL, MRI, } \\
\text { Lab data }\end{array}$ \\
\hline 03280056 & $18-60$ & Jul. 2019 & USA & BM-MSC-NTF & 200 & YES & III & IT & NR & $\begin{array}{c}3 \text { times bi- } \\
\text { monthly }\end{array}$ & DB & $\begin{array}{l}\text { ALS- } \\
\text { FRS-R } \\
\geq 25\end{array}$ & NM & ALSFRS, Biomarkers \\
\hline
\end{tabular}

Table 4: Ongoing registered clinical trials on MSCs based therapy for ALS: study designs. 
Citation: Saeed S, Soheila KR, Sima KR, Mandana MB, Hosein P, et al. (2018) A Comprehensive Review on the Application of Mesenchymal Stem Cell in the Treatment of ALS Patients. J Neurol Neurophysiol 9: 471. doi:10.4172/2155-9562.1000471

\section{References}

1. Rowland LP (2001) How amyotrophic lateral sclerosis got its name: the clinicalpathologic genius of Jean-Martin Charcot. Arch Neurol 58: 512-515.

2. Kurtzke JF, Beebe GW (1980) Epidemiology of amyotrophic lateral sclerosis 1. A case-control comparison based on ALS deaths. Neurology 30: 453-453.

3. Arthur KC, Calvo A, Price TR, Geiger JT, Chio A, et al. (2016) Projected increase in amyotrophic lateral sclerosis from 2015 to 2040. Nat Commun 7: 12408.

4. Kim Y-J (2017) Cost effectiveness analysis of riluzole for ALS in Ontario home care setting: University of Waterloo.

5. Trounson A, Thakar RG, Lomax G, Gibbons D (2011) Clinical trials for stem cell therapies. BMC Medicine 9: 52.

6. Malgieri A, Kantzari E, Patrizi MP, Gambardella S (2010) Bone marrow and umbilical cord blood human mesenchymal stem cells: State of the art. Int J Clin Exp Med 3: 248

7. Mareschi K, Rustichelli D, Comunanza V, De Fazio R, Cravero C, et al. (2009) Multipotent mesenchymal stem cells from amniotic fluid originate neural precursors with functional voltage-gated sodium channels. Cytotherapy 11: 534-547.

8. Wexler SA, Donaldson C, Denning-Kendall P, Rice C, Bradley Hows JM (2003) Adult bone marrow is a rich source of human mesenchymal 'stem'cells but umbilical cord and mobilized adult blood are not. Br J Haematol121: 368-374.

9. Bobis S, Jarocha DM (2006) Mesenchymal stem cells: Characteristics and clinical applications. Folia Histochemic Cytobiol 44: 215-230.

10. Beltrami AP, Cesselli D, Bergamin N, Marcon P, Rigo S, et al. (2007) Multipotent cells can be generated in vitro from several adult human organs. Blood 110: 3438-3446.

11. López-Cebral R, Silva-Correia J, Reis RL, Silva Oliveira JM (2017) Peripheral nerve injury: Current challenges, conventional treatment approaches, and new trends in biomaterials-based regenerative strategies. ACS Biomat Sci Engin 3 3098-3122.

12. Sidney LE, Branch MJ, Dunphy SE, Dua HS, Hopkinson A (2014) Concise review: evidence for CD34 as a common marker for diverse progenitors. Stem Cells 32: 1380-1389.

13. Mafi R, Hindocha S, Mafi P, Griffin MW (2011) Sources of adult mesenchymal stem cells applicable for musculoskeletal applications-a systematic review of the literature. Open Orthopaed J 5: 242.

14. Poloni M, Facchetti D, Mai R, Micheli A, Agnoletti L, et al. (2000) Circulating levels of tumour necrosis factor- $\alpha$ and its soluble receptors are increased in the blood of patients with amyotrophic lateral sclerosis. Neuroscience Letters 287: 211-214.

15. Chen K, Northington FJ, Martin LJ (2010) Inducible nitric oxide synthase is present in motor neuron mitochondria and Schwann cells and contributes to disease mechanisms in ALS mice. Brain Struc Func 214: 219-234.

16. Almer G, Vukosavic S, Romero NS (1999) Inducible nitric oxide synthase upregulation in a transgenic mouse model of familial amyotrophic lateral sclerosis. J Neurochem 72: 2415-2425.

17. Almer G, Guégan C, Teismann P, Naini A, Rosoklija G, et al. (2001) Increased expression of the pro-inflammatory enzyme cyclooxygenase-2 in amyotrophic lateral sclerosis. Annals Neurol 49: 176-185.

18. Garbuzova-Davis S, Willing AE, Saporta S, Bickford PC, Gemma C, et al (2006) Novel cell therapy approaches for brain repair. Prog Brain Res 157: 207-222.

19. Giunti D, Parodi B, Usai C, Vergani L, Casazza S, et al. (2012) Mesenchymal stem cells shape microglia effector functions through the release of CX3CL1. Stem Cells 30: 2044-2053.

20. Sun $H$, Bénardais $K$, Stanslowsky N, Thau-Habermann N, Hensel N, et al. (2013) Therapeutic potential of mesenchymal stromal cells and MSC conditioned medium in Amyotrophic Lateral Sclerosis (ALS)-in vitro evidence from primary motor neuron cultures, NSC-34 cells, astrocytes and microglia. PloS One 8: e72926.

21. Uccelli A, Moretta LV (2008) Mesenchymal stem cells in health and disease. Nature Rev Immunol 8: 726.

22. Kwon MS, Noh MY, Oh KW, Cho KA, Kang BY, et al. (2014) The immunomodulatory effects of human mesenchymal stem cells on periphera blood mononuclear cells in ALS patients. J Neurochem 131: 206-218.

23. Boruczkowski D, Gładysz D, Grudniak M, Kosterna KK (2016) Mesenchymal stem cells as a therapeutic option for patients with ALS. Gen Med 4: 2.

24. Joyce N, Annett G, Wirthlin L, Olson S, Bauer JA (2010) Mesenchymal stem cells for the treatment of neurodegenerative disease. Regen Med 5: 933-946.

25. Fan CG, Zhang QJ (2011) Therapeutic potentials of mesenchymal stem cells derived from human umbilical cord. Stem Cell Rev 7: 195-207.

26. Hegyi B, Környei Z, Ferenczi S, Fekete R, Kudlik G, et al. (2014) Regulation of mouse microglia activation and effector functions by bone marrow-derived mesenchymal stem cells. Stem Cells Dev 23: 2600-2612.

27. Karussis D, Karageorgiou C, Gowda-Kurkalli B, Kassis I, Vaknin-Dembinsky A, et al. (2010) Pilot Phase I/II clinical trial with autologous mesenchymal stem cells in patients with multiple sclerosis and amyotrophic lateral sclerosis pp: 10-17.

28. Gothelf Y, Kaspi H, Abramov NR (2017) miRNA profiling of NurOwn $\circledast$ : Mesenchymal stem cells secreting neurotrophic factors. Stem Cell Res The 8: 249.

29. Kumar V, Islam A, Hassan MF (2016) Therapeutic progress in amyotrophic lateral sclerosis-beginning to learning. Eur J Med Chem 121: 903-917.

30. Petrou P, Gothelf Y, Argov Z, Gotkine M, Levy YS, et al. (2016) Safety and clinical effects of mesenchymal stem cells secreting neurotrophic facto transplantation in patients with amyotrophic lateral sclerosis: Results of phase $1 / 2$ and $2 a$ clinical trials. JAMA Neurol 73: $337-344$

31. Kern R, Cudkowicz M, Berry J, Windebank A, Staff N, et al. (2018) NurOwn® phase 2 ALS trial: ALSFRS-R improvement is reflected in subscale domains (S38. 002). AAN Enterprises.

32. Aricha R, Kaspi H, Cudkowicz M, Berry J, Windebank A, et al. (2018) Modulation of csf mirnas in als phase 2 study participants treated with msc-ntf cells (NUROWN®)(S25. 005). AAN Enterprises.

33. Baek W, Kim Y, Koh S, Lim S, Kim H, et al. (2012) Stem cell transplantation into the intraventricular space via an Ommaya reservoir in a patient with amyotrophic lateral sclerosis. J Neurosurg Sci 56: 261-263.

34. Czaplinski A, Wojtkiewicz J, Siwek T, Habich A, Barczewska MW (2015) Mesenchymal stem cell (MSC) transplantation in patients with amyotrophic lateral sclerosis: Phase I/II clinical trial. Wiley River St. pp: 738-738.

35. Gabr H, Kishk N, Belal E, Aboelfotooh A (2017) Intrathecal autologous bone marrow derived mesenchymal stem cell therapy for amyotrophic lateral sclerosis. Cytotherapy 19: 199-200.

36. Mazzini L, Fagioli F, Boccaletti R, Mareschi K, Oliveri G, et al. (2003) Stem cell therapy in amyotrophic lateral sclerosis: A methodological approach in humans. Amyotroph Lateral Scler Other Motor Neuron Disord 4: 158-161.

37. Mazzini L, Mareschi K, Ferrero I, Vassallo E, Oliveri G, et al. (2006) Autologous mesenchymal stem cells: Clinical applications in amyotrophic lateral sclerosis. Neurol Res 28: 523-526

38. Mazzini L, Mareschi K, Ferrero I, Vassallo E, Oliveri G, et al. (2008) Stem cell treatment in amyotrophic lateral sclerosis. J Neurol Sci 265: 78-83.

39. Karussis D, Kassis I, Kurkalli BG, Slavin S (2008) Immunomodulation and neuroprotection with mesenchymal bone marrow stem cells (MSCs): A proposed treatment for multiple sclerosis and other neuroimmunological/ neurodegenerative diseases. J Neurol Sci 265: 131-135.

40. Mazzini L, Ferrero I, Luparello V, Rustichelli D, Gunetti M, et al. (2010) Mesenchymal stem cell transplantation in amyotrophic lateral sclerosis: A Phase I clinical trial. Exp Neurol 223: 229-237.

41. Gamez J, Carmona F, Raguer N, Ferrer-Sancho J, Martín-Henao GA, et al. (2010) Cellular transplants in amyotrophic lateral sclerosis patients: An observational study. Cytotherapy 12: 669-677.

42. Mazzini L, Vercelli A, Ferrero I, Boido M, Cantello R, et al. (2012) Transplantation of mesenchymal stem cells in ALS. Progress in brain research: Elsevier. Pp: 333-359.

43. Minguell J, Allers C, Jones J, Ganji S (2013) Allogeneic mesenchymal stem cells infusion to an ALS patient proved to be safe and capable to initiate clinical recuperation. Cell 1: e530. 
Citation: Saeed S, Soheila KR, Sima KR, Mandana MB, Hosein P, et al. (2018) A Comprehensive Review on the Application of Mesenchymal Stem Cell in the Treatment of ALS Patients. J Neurol Neurophysiol 9: 471. doi:10.4172/2155-9562.1000471

Page 10 of 18

44. Kim HY, Kim H, Oh KW, Oh SI, Koh SH, et al. (2014) Biological markers of mesenchymal stromal cells as predictors of response to autologous stem cell transplantation in patients with amyotrophic lateral sclerosis: an investigatorinitiated trial and in vivo study. Stem Cells 32: 2724-2731.

45. Oh KW, Moon C, Kim HY, Oh SI, Park J, et al. (2015) Phase I trial of repeated intrathecal autologous bone marrow-derived mesenchymal stromal cells in amyotrophic lateral sclerosis. Stem cells Transl Med 4: 590-597.

46. Rushkevich YN, Kosmacheva S, Zabrodets G, Ignatenko S, Goncharova N, et al. (2015) The use of autologous mesenchymal stem cells for cell therapy of patients with amyotrophic lateral sclerosis in Belarus. Bull Exp Biol Med 159: 576-581.

47. Staff NP, Madigan NN, Morris J, Jentoft M, Sorenson EJ, et al. (2016) Safety of intrathecal autologous adipose-derived mesenchymal stromal cells in patients with ALS. Neurol 87: 2230-2234.

48. Laghmouchi A, Hoogstraten C, van Balen P (2016) Physicians poster sessions.

49. Syková E, Rychmach P, Drahorádová I, Konrádová Š, Růžičková K, et al. (2017) Transplantation of mesenchymal stromal cells in patients with amyotrophic lateral sclerosis: Results of phase I/lla clinical trial. Cell Transplant 26: 647-658.

50. Henanff A, Giraudeau B, Baron G, Ravaud P (2006) Quality of reporting of noninferiority and equivalence randomized trials. JAMA 295: 1147-1151.

51. Cedarbaum JM, Stambler N, Malta E, Fuller C, Hilt D, et al. (1999) The ALSFRS-R: A revised ALS functional rating scale that incorporates assessments of respiratory function. J Neurol Sci 169: 13-21.

52. Stambler N, Charatan M, Cedarbaum JM (1998) Prognostic indicators of survival in ALS. Neurol 50: 66-72.

53. Magnus T, Beck M, Giess R, Puls I, Naumann M, et al. (2002) Disease progression in amyotrophic lateral sclerosis: Predictors of survival. Muscle Nerve 25: 709-714.

54. Badayan I, Cudkowicz ME (2002) Is it too soon for mesenchymal stem cell trials in people with ALS? Amyotrophic lateral sclerosis 9: 321-322.

55. Fagioli F, Mareschi K, Rustichelli D, Ferrero I, Mazzini L, et al. (2004) Mesenchymal stem cells in Amyotrophic lateral sclerosis pp: 36-36.

56. Mazzini L, Mareschi K, Ferrero I, Miglioretti M, Stecco A, et al. (2012) Mesenchymal stromal cell transplantation in amyotrophic lateral sclerosis: a long-term safety study. Cytotherapy 14: 56-60.

57. Blanquer M, Moraleda JM, Iniesta F, Gómez-Espuch J, Meca-Lallana J, et al. (2012) Neurotrophic bone marrow cellular nests prevent spinal motoneuron degeneration in amyotrophic lateral sclerosis patients: a pilot safety study. Stem Cells 30: 1277-1285.

58. Karussis D, Karageorgiou C, Vaknin-Dembinsky A, Gowda-Kurkalli B, Gomor JM, et al. (2010) Safety and immunological effects of mesenchymal stem cell transplantation in patients with multiple sclerosis and amyotrophic lateral sclerosis. Arch Neurol 67: 1187-1194.

59. Martino G, Franklin RJ, van Evercooren AB, Kerr DA, Group SC, et al. (2010) Stem cell transplantation in multiple sclerosis: Current status and future prospects. Nat Rev Neurol 6: 247

60. Forostyak S, Jendelova P, Kapcalova M, Arboleda D, Sykova E (2011) Mesenchymal stromal cells prolong the lifespan in a rat model of amyotrophic lateral sclerosis. Cytotherapy 13: 1036-1046.

61. Abdel-Wahab BA, Salama RH (2011) Venlafaxine protects against stressinduced oxidative DNA damage in hippocampus during antidepressant testing in mice. Pharmacol Biochem Behav 100: 59-65. 